\title{
Developing and Improving Student Non-Technical Skills in IT Education: A Literature Review and Model
}

\author{
Marcia Hagen * and David Bouchard \\ College of Management, Metropolitan State University, St. Paul, MN 55106, USA; \\ david.bouchard@metrostate.edu \\ * Correspondence: marcia.hagen@metrostate.edu; Tel.: +1-612-659-7236
}

Academic Editor: Valentina Dagiene

Received: 18 March 2016; Accepted: 10 June 2016; Published: 17 June 2016

\begin{abstract}
The purpose of this paper is to identify portions of the literature in the areas of Information Technology (IT) management, skills development, and curriculum development that support the design of a holistic conceptual framework for instruction in non-technical skills within the IT higher education context. This article review provides a framework for understanding how the critical success factors related to IT and Information Systems (IS) professional success is impacted by developing students' non-technical skills. The article culminates in a holistic conceptual framework for developing non-technical skills within the IT higher education context. Implications for theory and research are provided.
\end{abstract}

Keywords: computing education; non-technical skills; IT pedagogy; IT education

\section{Introduction}

Over the last several decades, Information Technology (IT) and Information Systems (IS) work and practice have become core to organizations' strategic imperatives. As a result, the IT and IS industries, and those individuals who manage and execute their strategy, have been more closely scrutinized. The recent attention to individual IT and IS professionals' skills has created a new urgency for improving what has been identified as a talent-gap at the state [1,2] national, and international [3] levels. This talent gap has been characterized as occupying two related areas: (a) gaps in professional development of individual's understanding of strategy; and (b) gaps in professional development of individuals with strong interpersonal and team skills [4] and knowledge of the impact of social and human capital [5]. Each of these gap areas result in perceived disparities between the needs of employers and the skills of recent IT and IS graduates, thus creating an increased awareness of possible deficits in the quality and employability of those graduates, and the ensuing effort to reduce it. Several states such as Minnesota and Rhode Island appear to be drawing similar conclusions, developing specific plans for the identification and reduction of said gaps. Importantly, a Rhode Island taskforce in IT and IS education identified non-technical skills deficits as the most important employer-identified skill gap in public higher education-based IT training [6] as well as gaps in how to appropriately employ IT to personalize educational opportunities for students in higher education [7]. Non-technical skills are viewed as both essential to the appropriate functioning of a business and important to the employability of recent graduates, but also necessary for students to feel confident in their abilities when entering the workplace [3]. It has been noted that there is increasing pressure on higher education to verify that students are, indeed, learning what is needed in both technical and non-technical areas [8]. If producing individual students who are employable in today's workplace is, truly, one of the major purposes of higher education and a driving force behind students' work [9], 
then it is critical for IT higher education to consider how non-technical skills apply within IT/IS education. The improvement of non-technical skills can be accomplished in a systematic way, within higher education.

In an effort to address the gaps noted above, several private sector, and consultancy-driven training initiatives, have been developed to address the issue of non-technical-skills development within IT. However the establishment of new methods of non-technical skill training and development into IT and IS curricula within higher education has been weak, at best [1,2]. IT and IS leaders and managers have been specifically noted as needing non-technical skill development, especially in leadership [2]. Importantly, while some of the courses that are designed to address technical IT/IS competencies include small quantities of pedagogy to address non-technical issues, it is clear that there is a need to develop a model for non-technical skill development that can be implemented across the curriculum and can be inserted in various experiential, experimental ways throughout the duration of required coursework. Please note that the work conducted to complete this review applies to both the IT and IS contexts. However, for the sake of clarity and consistency, only the term IT is referenced for the duration of the paper.

\section{Purpose Statement}

The call for improved relationship quality and the non-technical-skills needed to develop high level, quality relationships has been the topic of considerable discussion in both scholarly and popular literature $[10,11]$ and has been neglected for some time [12,13], and, while there have been several attempts within the private sector to work through identified soft-skills gaps within IT [14], as well as attempts to embed employable skills (including non-technical skills) into curricular design in higher education in general [10], few attempts have been made to identify how non-technical-skills training can be embedded into IT curricula at the post-secondary and graduate levels. Thus, the purpose of this paper is three-fold. First, the purpose is to identify areas considered to be critical to the successful completion of IT-related work. Second, the purpose is to create a typology of non-technical skills by identifying portions of the literature in the areas of IT management, skills development, and curriculum development. Finally, the purpose is to design a holistic conceptual framework within which to apply non-technical skills within the IT higher education context.

In order to address this purpose, first the literature review process will be discussed. Second, the literature on non-technical skills and critical success factors within the IT context will be identified. Third, a method for adapting non-technical skills to IT instruction within the context of a simulated project, and the resulting pedagogical model, will be discussed.

\section{Materials and Methods}

The purpose of this review is to examine the available literature in the area of IT non-technical skills in order to frame a connection between IT critical success factors, identified non-technical skills, and IT curricula in higher education. The following review of the literature was conducted according to the standards set for Integrative Literature Review [15]. While there is a paucity of research and scholarly writing in the area of IT non-technical skills, and even less that includes empirical research in this area, literature on critical success factors and general leadership skills are more plentiful. Thus, a review of the literature which examines these broader areas was conducted.

The literature review was conducted using the EBSCO Academic Search Premier and Business Source Premier databases, Emerald, and Google Scholar, as well as doing forward searches using Social Science Citation Index (SSCI) for the most recently published articles. Older articles were uncovered searching through reference lists of more current literature, as well as through the review of available reference lists. Databases that include conference proceedings were also searched. 
Keywords that reflected any theory or research in which IT non-technical skills could be included were searched during the literature review, including: Information Technology, IT, Information systems, IS, Management Information Systems, project, IT project management, non-technical skills, soft skills, leadership styles, success factors, critical success factors, effectiveness, education, higher education, and curriculum. As the search became broader, it yielded many pieces of literature outside the scope of this research. In particular, those articles that were about leadership and/or management outside of the IT context were not included in the review. A total of 98 articles were reviewed, primarily from scholarly journals and peer reviewed conference proceedings. Of those, 70 were included in this review; 28 were excluded from the current article because they lacked topical importance.

Literature review materials were grouped into themes based upon the conceptual linkages between phenomena identified, as suggested by Richards [16]. Themes were derived using accepted qualitative data analysis practice of analytical coding [16]. Results are provided in the sections below.

\section{The Development of Non-Technical Skills}

Non-technical skills are those interpersonal qualities and personal attributes that are critical for productive performance in today's workplace $[17,18]$. While there has been an effort to improve the development of effective IT professionals in several states, as noted above, it remains unclear how these skills can be developed by post-secondary and graduate students in a way that is both reflective of critical success factor literature, yet integrates the perceived needs of business leaders. Thus, this project is informed by research in technical areas that help to build a theoretical basis for non-technical curricula. A summary and typography of the literature on key non-technical skills is provided in Tables 1 and 2 in order to establish which non-technical skills are considered important within current literature. A thorough review of non-technical skills that are essential to the success of future IT professionals can be broken down into ten general areas of interest, with subareas covering specifics; these are listed and explained below.

\subsection{Non-Technical Factors Necessary for IT Success}

After thorough review of the literature, critical non-technical skills and other skills-related factors were identified. Individual critical factors are those concepts or phenomena which would directly impact the skills necessary for individual success; not all factors are skills in themselves, but each individual factor require an associated skill to address or mitigate that factor. Table 1 provides a listing of those non-technical skills found in the literature that are described as essential for IT success. The list is provided in alphabetical order below.

\subsection{An Explanation of Non-Technical Factors}

Using the theme development process identified in Section 2, based upon 18 key non-technical skills derived from literature review (as seen in Table 1) that are considered most important to professional IT work and practice. It includes a broad list of eighteen key non-technical skills necessary for success. These are addressed below. 
Table 1. Taxonomy of Non-Technical Skills.

1. Active listening

2. Communication (general)

3. Collaboration and

collaboration management

4. Communication technologies

5. Creativity and ideation

6. Critical thinking

7. Cultural knowledge

of communication

8. Cultural knowledge of self as related to culture

9. Cultures and their impact upon communication; National cultures

10. Diversity knowledge

(Understanding and Application)

11. Diversity (layers of

12. Ethics

13. Innovation

14. Interpersonal relationship management

15. Primary and subcultures of audience (knowledge of)

16. Problem solving

17. Professionalism

18. Re-framing of problems/situations
Communication technique that involves conceptual understanding, feedback, and confirmation of decoding of a message(s) via cognitive interpretation processes [19]. This understanding must include processes on the part of all parties; contributes to the effectiveness of group communication and group functioning.

Appropriate exchange of thoughts, ideas (both verbal and visual), and messages for the purpose of exchange of key information related to organizational and situationally specific problems and perspectives [20] in an effort to solve key problems.

Development and fostering of work-related relationships in which mutuality of benefit and risk-sharing take place within the context of information exchange [21,22]. Management of this collaboration involves the capturing and coordination of collaborative processes, often via technology [23]

Understanding of, and skills related to, the use of new technologies and media for the purpose of communication of complex information to organization members. Is related to social constructs within organizations and the social exchanges that take place within those [24] in an effort to gather information, enhance learning and knowledge, and/or build consensus.

Within the context of creative problem solving, the process of assessing multiple cognitive domains for the purpose of creative idea development [25]. Ability to test assumptions, make critical evaluations, and critically review systems and/or approaches [26].

Ability to communicate with audiences based upon understandings of communication patterns, processes, and expectations; knowledge of communication patterns exhibited by audiences, including issues of time, space, and contextual orientation [27]

Ability to understand and interpret preconceptions, biases, or displays of incongruence as related to one's culture and the culture (national or otherwise) of others. Culture in this case is defined as the totality of ones "words, actions, postures, gestures, tones of voice, facial expressions, the handling of time, space and materials ..." all of which are based upon historical, social and cultural contexts, and drive ones behavior and the meanings behind communications [27]. Understanding of how national cultures can impact patterns of thinking, feeling and acting [28], including the ability to understand attitude toward specific communication channels and the ability to apply and react appropriately to these preferences [29]

An understanding of, and appreciation for, diversity in race, sex, ability, and/or perspective for the purpose of improving overall organizational outcomes.

Knowledge and understanding of diversity from the perspective of the four-layer diversity model [30]; knowledge of definition of diversity, including personal, internal, external, and organizational dimensions [31].

"Rules, standards, codes or principles which provide guidelines for morally right behavior and truthfulness in specific situations" [32].

Creation or invention of novel, new or interesting processes, products, or technologies [33]

Related to relationship quality; ability to develop and manage relationships (including conflict management). Involves transactions in social relationships between two interacting partners [34].

Understanding what elicits an appropriate and/or expected response given the understanding of the subculture of the message give and/or receiver [27].

The rational, deliberate application of problem solving models in an effort to seek appropriate answers to problems [35]; the ability to integrate information from several different sources in order to improve organizational performance through the integration of multiple platforms, functions, and technologies. Conduct or qualities that promote value and respect for the profession and the individual representing that profession [36].

Restructuring one's mental models to better understand, interpret, and negotiate organizational problems and/or situations; understanding when to apply particular frames based upon a given situation, organizational culture, or particular point of view of other individuals who may be involved [37]. Or, the

application of limited information to improve decision making processes through the application of appropriate decision making schemas and/or organizing application of limited information to improve decision making processes through the
systems for the purpose of the identification of key issues and possible solutions [38]. 
Active listening is defined as a communication skill in which the listener gives all free attention to the speaker, actively processes the information received, then makes pertinent comments and asks appropriate questions [39,40]. Active listening has been identified as essential to the development of facilitative and collaborative teams (see number 1 above). Active listening contributes to the effectiveness of group communication, and is highlighted as essential to group functioning [41].

General communication skills (see number 2 above) are widely regarded as an important non-technical skill that IT professionals must possess. In fact, even newly-graduated students entering IT internships self-identify as needing to improve their communication skills in order to perform effectively in the workplace [42]. The improvement in communication includes the development of further skills in communicating via new technologies (see number 4 above) and with new media at the group and organizational level.

An understanding and willingness to use communication technologies (see number 4 above) is essential for the long-term success of IT professionals. These technologies, viewed as a way to provide organization members with a way to disseminate information. It is essential to the overall learning that takes place within an organization. Given the increasingly global scope of IT initiatives, and organizational strategies overall, innovative use of technology-based communications has increasingly become an imperative [43]. Knowledge sharing through communication technologies creates shared understanding, creates context for organizational knowledge and learnings, and mediates collaboration [44] (see number 3 above), all of which are essential components of successful IT implementation.

Creative thinking and ideation (see number 5 above) are relevant to the everyday responsibilities of an IT professional. Innovative and creative uses of IT is essential to creating competitive advantage for many organizations [45], and can be used to inspire new innovation and spark new ideas in the development of, and fulfillment of, customer requirements. Ideation, which is defined as the generation, development, and communication of a new idea [46] and innovation (see number 13 above), which is defined as the "creation of new knowledge and ideas to facilitate new business outcomes" [47] are also important. Both are essential to the development of creative problem solving tactics and techniques [48], especially in new product and new process design [49].

Critical thinking skills (see number 6 above), defined as "reflective and reasonable thinking that is focused on what to believe or do" [50], was also included in the review findings. In particular, critical thinking that includes the ability to test assumptions, make critical evaluations, and critically review systems approaches [51]. Critical thinking skills are essential for the implementation of thorough and effective IT systems. Those individuals who are able to think critically are better able to help develop a learning organization, which requires the ability for organization members to critically question assumptions and develop the double-loop learning essential to strong organization learning and knowledge creation [52].

An understanding of diversity (see number 11 above), and its impact upon various portions of an IT project, including its deployment and execution, is essential (see number 10 above). Diversity can impact the perceptions of project team members [53], as well as impact end user perceptions [54] (see number 15 above). Additionally, gender and cultural differences (see number 3 above) have major impacts on both communication and group process (see numbers 7 and 9 above). Possessing a strong level of emotional intelligence and deep understanding of how diversity impacts work processes is key to an IS managers' performance [55] (see number 8 above). It is important that IT professionals are able to identify the opportunities that arise when diverse individuals are involved in IT planning and execution [53], with IT professionals' experiential diversity having a positive impact upon user adoption [56]. 
The ability to work interpersonally with individuals both intra and inter-departmentally is considered an important non-technical skill [57], and is related to the relationship quality among IT ranks and with others in the organization (see number 14 above). Relationship quality is generally concerned with three areas of relationship functioning: the quality of interpersonal communications, level of trust, and overall satisfaction with the relationship [58]. An IT professional's ability to develop and manage relationships is key to professional success, and it is important for students to understand the mechanisms by which good interpersonal relationships can be built [59].

Problem solving skills (see number 16 above) are important to the process of developing and implementing complex IT projects. IT professionals are often called upon to be problem solvers who have the ability to integrate information from several different sources in order to improve organizational performance [4]. This is accomplished through the integration of multiple platforms, functions, and technologies.

Professionalism (see number 17 above) and ethics (see number 12 above) are essential to the growth and development of IT professionals. A full and critical understanding of ethics, including the ethical implications of IT, and its possible impact upon specific social classes and society, in general [60], is essential to developing the next generation of IT professionals and leaders.

Reframing of problems and situations (see number 18 above) to fit multiple mental models is an essential skill of any manager, IT included. Reframing is the process of restructuring one's metal model to better understand, interpret, and negotiate organizational problems and/or situations; understanding when to apply particular frames based upon the situation, organizational culture, and particular point of view of other individuals who may be involved [37]. Within this process is the cognizant application of limited information to improve decision-making processes through application of appropriate decision-making schemas and/or organizing systems for the purpose of the identification of key problems and possible solutions [38]. Knowledge and skills in this area are important because they help individuals to understand multiple perspectives and communicate effectively within and among the many frameworks from which other organizational members and leaders may be viewing or perceiving a situation or problem [61].

Each of the non-technical skills referenced above is essential to the success of IT professionals. These skills provide a mechanism for IT professionals to cope with the increased complexity of IT infrastructures. Importantly, collaboration, influence, and problem definition are key to the role of IT and require important non-technical skills that will help to create a project-centered environment in which IT professionals are able to work among themselves, and with other functions and areas of the organization, to produce the best possible IT product [21] (see Table 1).

\subsection{Critical Success Factors in IT: A Project-Individual Perspective}

Those factors that have been identified within the literature as "critical" to IT success help to reinforce the call for strong skills in non-technical skills [12,14]; the identification of IT critical success factors helps to further delineate those areas of greatest need, as well as those that are most germane to non-technical skills. Critical success factors (CSFs) are defined as those areas in which "results, if they are satisfactory, will ensure successful performance" [33]. Importantly, they are critical areas in which thorough planning and excellent execution must take place in order to achieve high levels of success. Table 2 reviews several pieces of research that identify critical success factors for IT implementation. 
Table 2. Non-technical skills model as related to critical success factors.

\begin{tabular}{|c|c|c|c|}
\hline Area & Critical Success Factors & Author & Non-Technical Skill-Individual Level \\
\hline \multirow{6}{*}{ Organizational factors } & Top management support & $\begin{array}{l}\text { Ariyachandra and Frolic [61]; Lawson-Body, } \\
\text { Willoughby, Mukankusi and Logossah [62]; } \\
\text { Biehl [63]; Wong [64]; Poon and Wagner [65]; } \\
\text { Sommers and Nelson [66]; Nah, Lau and Kuang [67] }\end{array}$ & $\begin{array}{l}\text { Interpersonal relationship management; Reframing skills; } \\
\text { Communication (general); Professionalism; Ethics }\end{array}$ \\
\hline & $\begin{array}{l}\text { Project sponsorship/ } \\
\text { champion }\end{array}$ & $\begin{array}{l}\text { Nah, Lau and Kuang [67]; Poon and Wagner [65]; } \\
\text { Frolick and Ariychandra [68]; Sommers and } \\
\text { Nelson [66] }\end{array}$ & $\begin{array}{l}\text { Interpersonal relationships; Communication (general); } \\
\text { Professionalism; Reframing skills }\end{array}$ \\
\hline & $\begin{array}{l}\text { Governance/management } \\
\text { systems in place }\end{array}$ & $\begin{array}{l}\text { Lee, Shim and Kim [69]; Ariyachandra and } \\
\text { Frolic [61]; Nah, Lau and Kuang [67] }\end{array}$ & $\begin{array}{l}\text { Interpersonal relationship management; Communication (general); } \\
\text { Communication technologies; Critical thinking; Innovation }\end{array}$ \\
\hline & $\begin{array}{l}\text { Culture of sharing and } \\
\text { creation }\end{array}$ & Malhotra [44] Sommers and Nelson [66]; Wong [64] & $\begin{array}{l}\text { Interpersonal relationship management; Active listening; } \\
\text { Communication (general); Communication technologies; Critical } \\
\text { thinking; Innovation and ideation; Understanding and Application } \\
\text { of Diversity Knowledge; Reframing skills }\end{array}$ \\
\hline & $\begin{array}{l}\text { Culture of } \\
\text { interdepartmental } \\
\text { collaborations }\end{array}$ & Sommers and Nelson [66]; & $\begin{array}{l}\text { Interpersonal relationship management; Active listening; } \\
\text { Communication (general); Communication technologies; Critical } \\
\text { thinking; Innovation and ideation; Understanding and Application } \\
\text { of Diversity Knowledge }\end{array}$ \\
\hline & $\begin{array}{l}\text { Culture that supports } \\
\text { change }\end{array}$ & Nah, Lau and Kuang [67] & $\begin{array}{l}\text { Interpersonal relationship management; Active listening; } \\
\text { Communication (general); Reframing skills; Communication } \\
\text { technologies; Critical thinking and innovation; Problem solving; } \\
\text { Understanding and Application of Diversity Knowledge; Ethics }\end{array}$ \\
\hline \multirow{5}{*}{$\begin{array}{l}\text { Strategic factors } \\
\text { related to IT project }\end{array}$} & $\begin{array}{l}\text { Clear strategy } \\
\text { development }\end{array}$ & $\begin{array}{l}\text { Rockart [33]; Malhotra [44]; Nah, Lau and } \\
\text { Kuang [67]; Sommers and Nelson, } 2001 \text { [66]; } \\
\text { Ariyachandra and Frolic [61]; Lee, Shim and } \\
\text { Kim [69]; Wong [64] }\end{array}$ & Critical thinking; Innovation and ideation; Problem solving \\
\hline & $\begin{array}{l}\text { Team with appropriate } \\
\text { expertise }\end{array}$ & $\begin{array}{l}\text { Ariyachandra and Frolic [61]; Chow and Cao [70]; } \\
\text { Poon and Wagner [65]; Sommers and Nelson [66]; } \\
\text { Nah, Lau and Kuang [67] }\end{array}$ & $\begin{array}{l}\text { Active listening; Reframing skills; Critical thinking; Problem solving; } \\
\text { Understanding and Application of Diversity Knowledge; } \\
\text { Communication technologies; Professionalism; Ethics }\end{array}$ \\
\hline & Team motivation & Wong [64]; Chow and Cao [70] & $\begin{array}{l}\text { Interpersonal relationship management; Reframing skills; Active } \\
\text { listening; Critical thinking; Problem solving; Understanding and } \\
\text { Application of Diversity Knowledge }\end{array}$ \\
\hline & $\begin{array}{l}\text { Linkages to business } \\
\text { needs }\end{array}$ & Poon and Wagner [65] & Active listening; Critical thinking; Problem solving \\
\hline & $\begin{array}{l}\text { Technological } \\
\text { infrastructure in place }\end{array}$ & $\begin{array}{l}\text { Poon and Wagner [65]; Wong [64]; Lee, Shim and } \\
\text { Kim [69]; }\end{array}$ & Active listening; Critical thinking; Problem solving \\
\hline
\end{tabular}


Table 2. Cont

\begin{tabular}{|c|c|c|c|}
\hline Area & Critical Success Factors & Author & Non-Technical Skill-Individual Level \\
\hline \multirow{6}{*}{ IT leadership factors } & $\begin{array}{l}\text { Effective } \\
\text { communication/skills } \\
\text { (including frequency) }\end{array}$ & $\begin{array}{l}\text { Ariyachandra and Frolic [61]; Biehl, } 2007 \text { [61]; } \\
\text { Malhotra, } 2001 \text { [44]; Rockart [33] }\end{array}$ & $\begin{array}{l}\text { Interpersonal relationship management; Active listening; Problem } \\
\text { solving; Understanding and Application of Diversity Knowledge; } \\
\text { Communication (general); Reframing skills; Communication } \\
\text { technologies; Professionalism; Ethics }\end{array}$ \\
\hline & $\begin{array}{l}\text { Ability to perform } \\
\text { appropriate human } \\
\text { resource management } \\
\text { practices }\end{array}$ & Wong [64]; Nah, Lau and Kuang [67]; & $\begin{array}{l}\text { Interpersonal relationships; Active listening; Problem solving; } \\
\text { Understanding and Application of Diversity Knowledge; } \\
\text { Communication (general); Professionalism; Ethics }\end{array}$ \\
\hline & $\begin{array}{l}\text { Ability to champion } \\
\text { IT/project }\end{array}$ & Ariyachandra and Frolic [61]; & $\begin{array}{l}\text { Interpersonal relationship management; Reframing skills; Active } \\
\text { listening; Problem solving; Communication (general); } \\
\text { Professionalism; Ethics }\end{array}$ \\
\hline & Management of resistance & $\begin{array}{l}\text { Poon and Wagner [65]; Frolick and } \\
\text { Ariychandra [68]; Ariyachandra and Frolic [61] }\end{array}$ & $\begin{array}{l}\text { Interpersonal relationship management Active listening; Reframing } \\
\text { skills; Problem solving; Understanding and Application of Diversity } \\
\text { Knowledge; Communication (general); Communication } \\
\text { technologies; Professionalism; Ethics }\end{array}$ \\
\hline & $\begin{array}{l}\text { Ability to recognize } \\
\text { training needs }\end{array}$ & $\begin{array}{l}\text { Nah, Lau and Kuang [67]; Wong [64]; Lawson-Body, } \\
\text { Willoughby, Mukankusi and Logossah, } 2011 \text { [62] }\end{array}$ & $\begin{array}{l}\text { Interpersonal relationship management; Active listening; Problem } \\
\text { solving; Understanding and Application of Diversity Knowledge; } \\
\text { Communication (general); Ethics }\end{array}$ \\
\hline & Project management skills & $\begin{array}{l}\text { Lee, Shim and Kim [69]; Sommers and Nelson [66]; } \\
\text { Nah, Lau and Kuang [67] }\end{array}$ & $\begin{array}{l}\text { Interpersonal relationship management; Active listening; } \\
\text { Communication (general); Communication technologies; Critical } \\
\text { thinking; Innovation and ideation; Understanding and Application } \\
\text { of Diversity Knowledge }\end{array}$ \\
\hline \multirow[t]{2}{*}{$\begin{array}{l}\text { Customer/vendor } \\
\text { factors }\end{array}$} & $\begin{array}{c}\text { User } \\
\text { acceptance/awareness }\end{array}$ & $\begin{array}{l}\text { Lawson-Body, Willoughby, Mukankus and } \\
\text { Logossah, 2011 [62]; Ariyachandra and Frolic [61]; } \\
\text { Lee, Shim and Kim [69] }\end{array}$ & $\begin{array}{l}\text { Interpersonal relationship management; Active listening; Problem } \\
\text { solving; Understanding and Application of Diversity Knowledge; } \\
\text { Communication (general); Communication technologies; } \\
\text { Professionalism; Ethics }\end{array}$ \\
\hline & $\begin{array}{l}\text { Customer relationship } \\
\text { management }\end{array}$ & Chow and Cao [70] & $\begin{array}{l}\text { Interpersonal relationships; Active listening; Critical thinking; } \\
\text { Reframing skills; Problem solving; Understanding and Application } \\
\text { of Diversity Knowledge; Communication (general); Communication } \\
\text { technologies; Professionalism; Ethics }\end{array}$ \\
\hline
\end{tabular}


Each of the non-technical skills referenced above is essential to the ability of IT professionals, especially managers, to cope with the increased complexity of IT infrastructures. For example, collaboration, influence, and problem definition are key to the role of IT professionals, and require important non-technical skills that will help to create a project-centered environment in which IT professionals are able to work among themselves, and with other functions and areas of the organization, to produce the best possible IT product [21]. First, using the thematic review process identified in Section 2, critical success factors were placed into themes based on whether the CSF was primarily affiliated with organizational, strategic, leadership, or customer/vendor factors. Next, a review of the information derived from Table 1 was completed and non-technical skills were placed into thematically-derived CSF categories. Categorization was based on authors' understanding of the non-technical skills necessary for each of the critical success factors. Thus, Table 2 integrates those critical success factors (CSF) identified within the literature with the non-technical-skills identified in Table 1. Table 2 confirms that few CSFs can be accomplished by an individual who lacks key non-technical skills; success at the IT project level necessitates non-technical skills at the individual level. Table 2 integrates those IT critical success factors identified within the literature to the non-technical skills needed to realize success within the particular CSF domains.

As can be seen from Table 2, several of the most widely-reported critical factors can (and must) be addressed with non-technical (in addition to technical) skills. The skills identified above give rise to important ways to address those areas critical to the effective implementation of IT. Thus, it is suggested that curricula be identified that can help to establish these important skills in new IT professionals.

\section{Project Simulation: A Model for Teaching}

In earlier sections we have identified several non-technical skills needed for IT professionals to be successful in the workplace. However, simply knowing which skills are needed is not enough; IT educators must also have a plan for implementing instruction on those skills in the IT classroom. We suggest IT project simulation as a vehicle for doing that for the reasons outlined below.

The literature offers several different options for teaching critical skills to IT professionals-those have primarily been centered on workplace training, rather than within higher education curricula. Reflection on experience, formalized training, and the use of a coach or mentor [71] have all been identified as developmental tools for workplace development. However, the ways in which critical skills are taught within IT higher education has been lackluster, at best [72], when attempting to teach IT project management skills with traditional, theory-based methods. Since traditional pedagogical methods may not be conducive to learning in this area [71], it is suggested that practicing non-technical skills has the best chance for successful learning among IT students. Specifically, it has been stated that because projects are core to the larger field of IT, a simulated project should be used to illustrate the fundamental principles of IT project management [72-74].

The use of project-based pedagogies continues to be relevant as a basis for teaching and training within IT education [74]. As first suggested by Deininger and Schneider [75], the use of a simulated project is a good way for IT students to learn important skills. Inclusion of a generic project as the framework for IT education has since become seen as an important way for students to master both the skills needed to complete their work, as well as the project management skills needed to manage the overall flow and steps of traditional IT projects.

Although simulated projects have been suggested for use as a pedagogical method for teaching IT students for several years [74], they have been traditionally used as a method to teach the technical skills of IT. As was suggested by Beard, Schweiger and Surendran [9], the pedagogical methods used to teach non-technical skills to IT students should take place in a strategic and well-organized fashion. Specifically, it is essential that the goals and objectives of the learning process, activities and methods of the learning components, the outcomes and evaluation, and necessary actions all be considered when attempting to develop sound pedagogical methodologies. Engaged at the curricular, course, and course component levels, as suggested by Blumenberg, Biemborn and Koenig [12], non-technical skills 
can be integrated within an IT curriculum in multiple ways using multiple techniques. Scholars call for pedagogy and curriculum that more strongly reflects those situations and circumstances that students will experience on the job-and that this can be accomplished through project-based learning and educating for specific skill-sets [11,76-78]. The implementation of student practice for specific non-technical skill-sets into the project context will aid in anchoring the non-technical skills to those specific areas in which students will need to introduce and exhibit these skills in a real-world project scenario.

Based on the literature noted above, it is suggested that any non-technical skills training be integrated into a generic IT project model. Additionally, it is suggested that the implementation of the project model, and the non-technical skills training therein, be implemented in a four-step instructional process that mimics the process used in a workplace IT project. Thus, the following is a general model for implementing a project simulation into an IT program. Used as a pedagogical element in which to insert non-technical skills training, the model includes a four-step process. This curricular model is similar to other oft-used IT process models such as the one suggested by Nunamaker, Chen, and Purden [79].

1. Conceptualization, (Concept-Problem Identification Process): In this step, in addition to the generally-accepted steps of problem identification, students will also be expected to display those non-technical skills necessary to successfully complete the process.

2. Software or system development (Development-Cognitive Framing Process): In this step, in addition to general software or systems development, students will also be expected to display those non-technical skills related to cognitive reframing (as seen in Table 1).

3. Implementation (Implementation-Social Intuition-Self-Monitoring Process): In this step, in addition to the generally-accepted technical process of software or systems implementation, students will also be expected to display those non-technical skills related to social and self-influences that help to establish and confirm shared understanding and shared vision for an IT project.

4. Evaluation (Evaluation and Interpretation): In this step, in addition to the generally-accepted technical process of project evaluation, students will also be expected to display those non-technical skills that will help to re-engage stakeholders in any additional problem identification processes necessary to bring the simulated IT project to successful completion.

Based upon this approach, the non-technical skills described in Table 1 could be implemented via learning components into those project steps (steps 1-4) in which they would need to be executed, as shown in Figure 1.

\subsection{Integration of Non-Technical-Skills into Core IT Curriculum: An Algorithmic Approach}

Discussions surrounding the issue of curriculum often give rise to debate regarding how to implement the teaching of non-technical skills, such as those suggested in Section 3.1, into a technically-based curriculum, like IT. Several pieces of scholarly IT literature help to elucidate one strong method for doing so. Scholars have described the nature of algorithmic thinking and algorithmic understanding of information (for example, [80]). Algorithmic thinking was originally theorized as a way to deal with the complexity of binary strings of numbers that could continue infinitely. Historically, algorithmic theory was developed as a systematic method for theorists to define the randomness within those strings; it is now applied to software and software development as a way to limit the amount of information needed to generate solutions [80], and is used widely throughout IT as a method for solving recurring problems [81]. We suggest that algorithms may, too, be used to guide thinking and solve problems related to the seeming randomness of socially-based non-technical-skills. Thus, we suggest that IT students apply their understanding and knowledge of algorithms to social situations in an effort to build non-technical skills. 


\section{IT Professionals' Skills Development: A Cognitive Model}

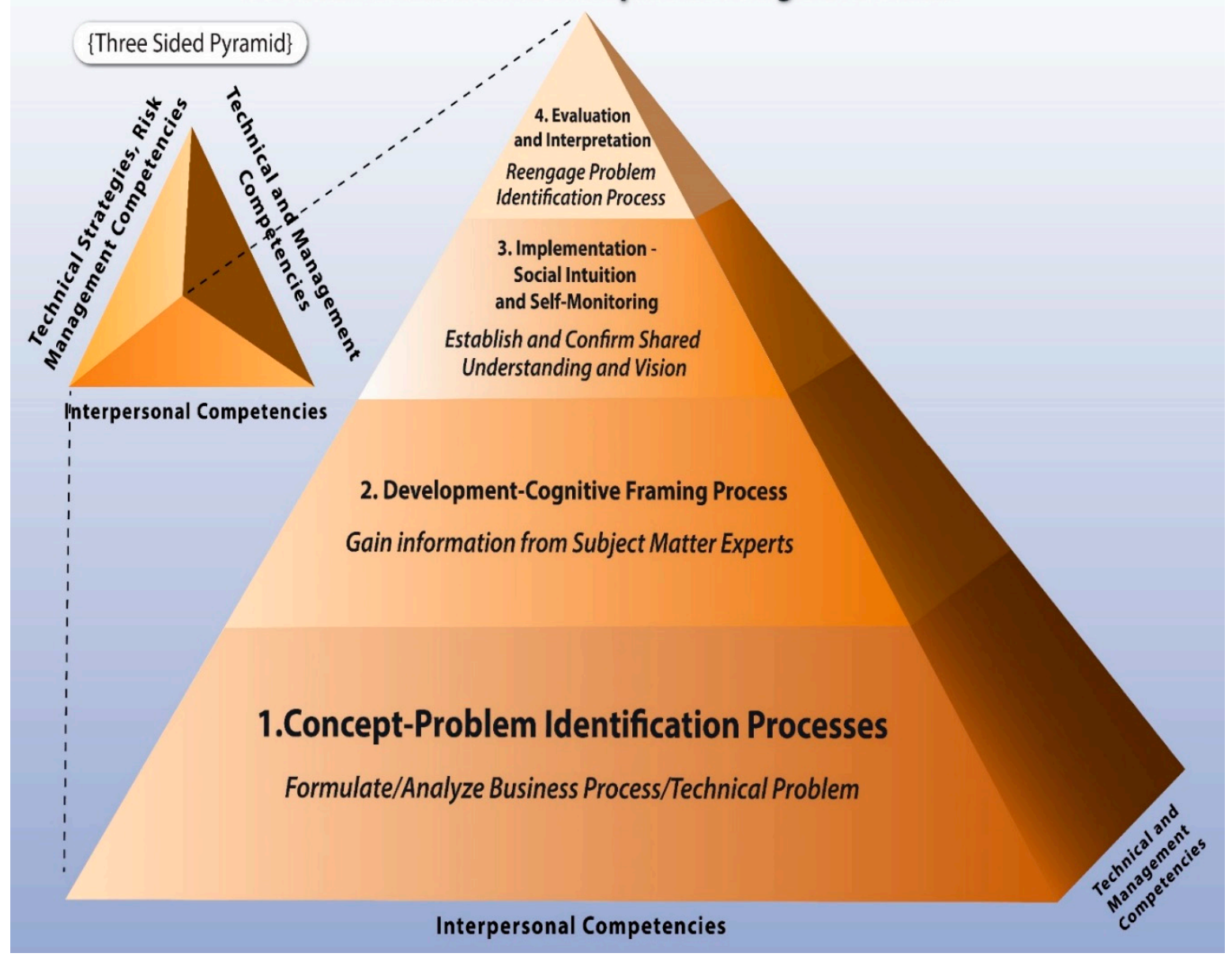

Figure 1. Systems Development Life Cycle Project Framework with Algorithmic CognitiveSocial Processes.

It is well established that so-called soft skills require a unique, nearly constant string of decision points throughout several iterations of communication (see [82]). However, infinite inputs, cognitive heuristics, and schemata all get in the way of perfect decision making within a communicative context [82]. Thus, it seems possible that an algorithmic process, similar to those used to simplify complex strings of information, could be used to simplify these complex communication and social processes.

A growing body of literature within IT establishes algorithms as a useful teaching tool. The integration of algorithms has been suggested as a new key trend in education-especially in the area of early childhood, where they are implemented as a way to help children develop ready solutions to specific problems using step-wise decision processes [82]. This process has been utilized in early childhood and K-12 education for many years with good results [83]. The implementation of this strategy for non-technical-skills training is suggested by these authors as a way of simplifying the complex nature of communicative decision making [84], thus reducing the complexities in cognitive-social processes inherent in non-technical skills type activities.

\subsection{Collaborative Problem Identification}

One of the first steps of IT project implementation is problem identification. Relatively well established within the literature, problem identification should be a collaborative process. Collaboration, in this case, is a learning activity in which interactions between individuals in a 
group. It is a process in which the amount of learning that takes place is related to the level of effort that group members devote to the internal and interactional processes; it results in the development of a shared understanding of the domain of interest [85]. Problem identification is one of the most important processes within the problem solving domain of IT work. It has been suggested that group model building is one way in which ill-defined issues (sometimes called "messy problems") can be discussed in a formalized way. IT leaders often deal with messy problems, those areas in which a solution is not evident; some stakeholders may even call into question whether a problem exists at all [86]. Importantly, the problem identification process is enhanced when stakeholders are allowed to participate in the identification of significant IT problems. It is essential for IT leaders to understand methodologies for problem identification, as well as be able to recognize multiple stakeholder perspectives and create collaborative forums around which multiple stakeholders can contribute to the definition of IT problems. The shared definition of these problems requires specific skills in areas such as conflict resolution, communication, and negotiation techniques, just to name a few [87]. Without the requisite skills, identified alternatives will only result in partial solutions that neither meet the needs, nor garners the support, of stakeholders.

The development of a set of standard questions and/or questioning techniques can be taught using an algorithmic method. Employing the list of critical success factors, in association with those non-technical skills identified in the IT literature, we can help students to understand and become more adept at screening potential problems and creating a standard procedure by which they can identify the most appropriate, collaboratively-developed problem from which to design IT projects.

Examples of how the algorithmic method could be combined with technical areas of instruction include significant rehearsal and live exercise. By providing students with opportunities for practicing non-technical skills in ways that provide both meaningful real-time and retrospective feedback using multiple media (including video), the skills can move from academic to internalized abilities. Algorithmically, students can be taught skills, such as conflict resolution, active listening, and general communications skills, in order to improve their ability to traverse the collaborative problem-identification process.

\subsection{The Importance of Cognitive Frameworks}

As suggested earlier, the reframing of problems and situations to fit multiple mental models is an essential skill of any manager, IT included. Cognitive frameworks are those biases, heuristics, and other mental models that allow each of us to quickly analyze information to come to a fast and appropriate decision [37]. This skill, applied to IT, is an essential part of understanding and negotiating the many and various decision-making processes that an IT professional must go through when working with information technologies and systems development, creation, and implementation-especially when they involve multiple stakeholders. IT professionals' understanding of their own cognitive frameworks is essential to the collaborative problem identification process, IT leaders must create an understanding of (a) what frameworks they have and use currently when making a decision; and (b) when and how to apply particular frames based upon a particular situation, organizational culture, or particular point of view of others [37]. The process of becoming cognizant of stakeholders' frames of reference and perspectives help individuals to become aware of how others perceive a problem, and how they may perceive and analyze possible solutions to that problem [61].

Along this vein, it is also important that people understand their own decision-making frames. During the course of their work, IT leaders are often faced with multiple alternatives that include inadequate, often subjective, data. This results in IT professionals processing decision alternatives that include multiple layers of subjective information-perceptions of individuals, the environment, and the overall organization - that are based upon subjective information. This information ultimately can lead to poor decision-making [88]. These result in two problematic decision-making issues: biases and heuristics. Biases such as confirmation bias, the bias of hindsight, and the premature termination of search $[89,90]$ create an environment in which the identified problem and the list of potential solutions become less effective. 
Given the multiple pitfalls that IT professionals face during the course of their work, IT curriculum must develop students' ability to cognitively frame problems and solutions from the perspective of both (a) understanding others' frames; and (b) an awareness of the biases and heuristics which may cloud their own problem identification, solution generation, and decision-making processes if IT programs indeed intend for IT leaders to make excellent decisions. Importantly, several frameworks, including the one set out by Bolman and Deal [37] lend themselves of algorithmic thinking. That is, they help students to methodically view a situation from several lenses in order to understand, identify, and react to both their own, and others', frames effectively. One example of an effective way to direct the algorithmic structure for understanding and responding to cognitive frameworks is provided by Bolman and Deal [37], who provide a set of questions that help students to review a situation in a systematic way, and select a frame from which to confront it.

\subsection{Social Intuition and Contextual Awareness as a Function of Self-Monitoring}

In addition to understanding how ones' biases and heuristics may be impacting IT practices, it is also important for IT leaders have an understanding of and consciousness of how social contexts may be impacting the overall problem-solving process. This understanding, and the social intuition and self-monitoring processes that drive that understanding, are essential for IT leaders' ability to work with others effectively. Importantly, while social intuition and self-monitoring are not part of the current IT literature, they are a part of the larger management scholarship, and apply directly to the work of IT professionals. According to Davidson and Begley [91], a great deal of what happens is related to an individual's ability to pick up social signals, with the help of facial expressions and body language. In addition, they suggest that our ability to read social cues and then develop an appropriate response to those cues, which are based upon very specific contexts, is helpful in creating a social environment within the workplace in which emotions and perceptions are better understood.

Similarly, there has been a great deal of research on self-monitoring within the organizational context. Self-monitoring is the ability to regulate one's self-presentation "by tailoring their actions in accordance with immediate situational cues" [92]. The notion of self-monitoring may or may not be related to an individual's desire to control a situation [93], however, self-monitoring as a skill has been attributed to both ability and motivation. That is, one may be either unable to respond to external cues, or unwilling to do so. Self-monitoring has been studied at length, and has been found to be positively related to subjective job performance outcomes as well as the expression of leadership; individuals who are exceptional self-monitors are seen as more "leader-like" [94].

In addition to performance, self-monitoring as a skill is important because it allows for the establishment and maintenance of effective work relationships [94]. Self-monitoring has been linked to specific leadership functions, such as building commitment and creating alignment [94], which are essential to an IT professional's success on the job. Thus, the acuity to read others, relate that to social contexts, and monitor self-behaviors based upon the work environment is especially important for future IT leaders who will be expected to perform in a myriad of contexts, and with individuals from various levels and functions within an organization. This responsibility requires that one must be able to work with others in a collaborative way, acknowledging and understanding how one's own mental frame and social behaviors, and the frame of others, will impact project decisions.

Again, within the context of higher education, the development of a sequential set of standards by which to test and understand the level and type of self-monitoring most appropriate to a context or setting is crucial. The development of an algorithmic way by which to address these within the IT curriculum may be an example of executed through a series of 'thought experiments' as defined by Dennett [95].

The important non-technical processes of (a) problem identification; (b) cognitive framing; and (c) understanding of social contexts in order to read and respond appropriately to social cues through self-monitoring are all important to workplace success for IT professionals. Each of these can and should be practiced within the systems development life cycle, as noted above. The systems 
development life cycle is a well-known conception that described the life cycle of a generalized IT project. It includes the formulation of a problem, information gathering, and the creation of a shared vision that must take place during the concept, development, and implementation phases of an IT project [96].

The following sections includes a detailed reporting of each of the four key IT project simulation steps. Each of the steps (taken from Figure 1 above) indicates both the technical step required of students during the project simulation, as well as the key non-technical skills required to successfully accomplish that step (as noted in Tables 1 and 2). Figures 2-5, described both the technical step required for completing a simulated student project and a listing of those key non-technical skills required to successfully complete that step (based on the linkages found in Table 2).

The technical project requirements and corresponding non-technical skill requirements were established through a review of the areas listed in column 1 of Table 2; a thoughtful review of the themes derived in the initial literature search revealed key areas of interest for each of the simulated project steps.

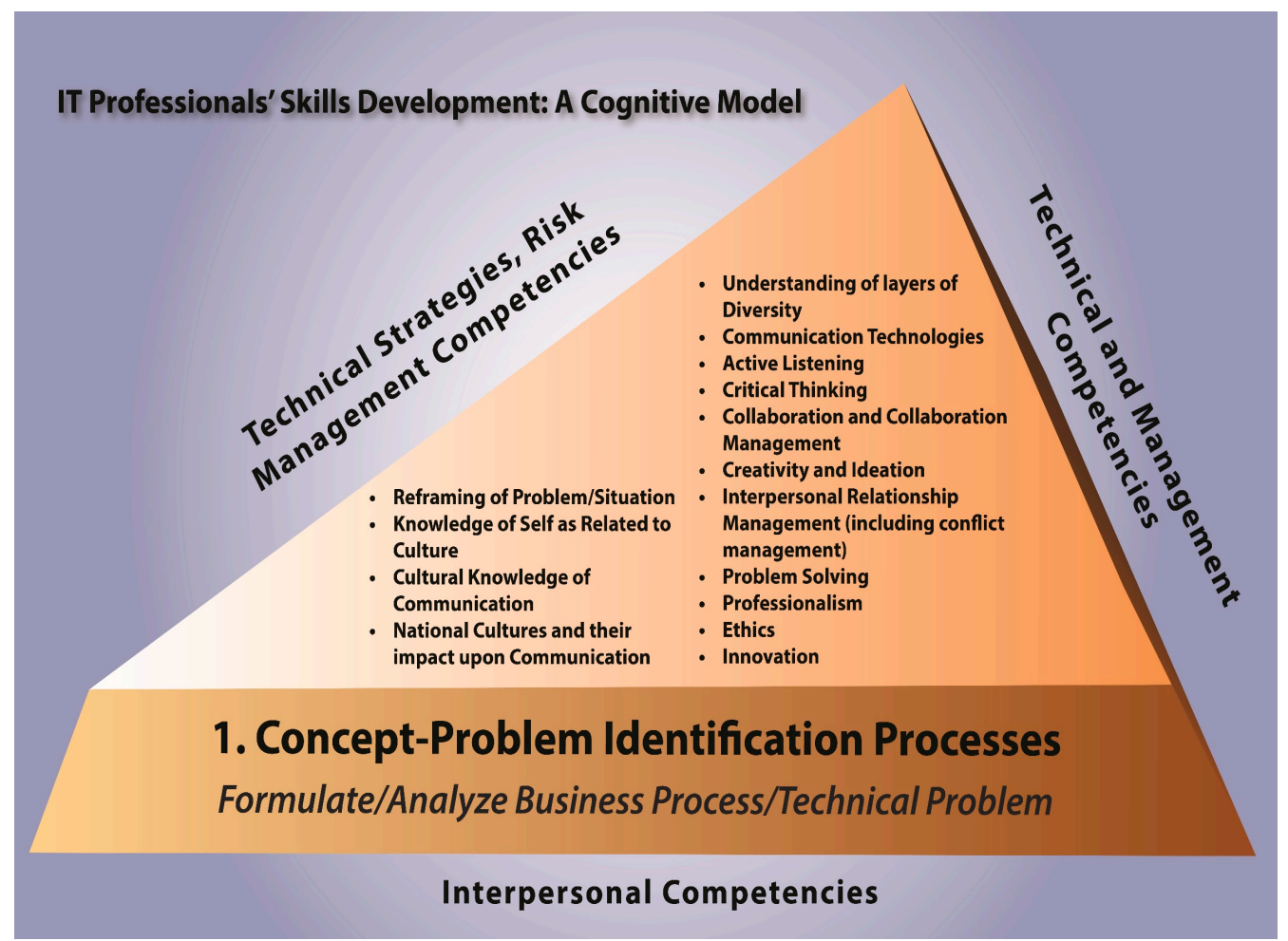

Figure 2. Illustration of the Necessary Non-technical Skills for Step 1: Problem Identification Process within a simulated IT Project Systems Development Life Cycle Context.

\subsection{Non-Technical Skills as a Function of Project Processes}

The use of project simulation as a pedagogical technique for improving the understanding of the role of IT managers is one that has been used for some time. It is helpful in providing a set of guideposts by which students can better understand the entire IT project process. Yet, while this has been used as a tool to instruct in technical skills areas for some time, we suggest that it also has the potential for instructing in areas of non-technical skill as well. Within each of the project phases, (concept, development, implementation, and evaluation) a unique set of non-technical skills is necessary for completing project tasks appropriately and effectively. The need for inclusion of non-technical skills in this area becomes even more evident when considering that an IT professional's ability to complete a project is dependent upon the cognitive-social processes of collaborative problem 
identification, social intuition, and contextual awareness, and formulating cognitive frameworks-all of which are social and non-technical in nature. For instance, in order to build a collaborative problem identification process, it is necessary to have (a) excellent communication skills; (b) the ability to reframe a problem or situation; and (c) a keen understanding of culture and its impact upon communication, among other areas. Thus, we suggest several non-technical skills are needed to complete these cognitive-social processes.

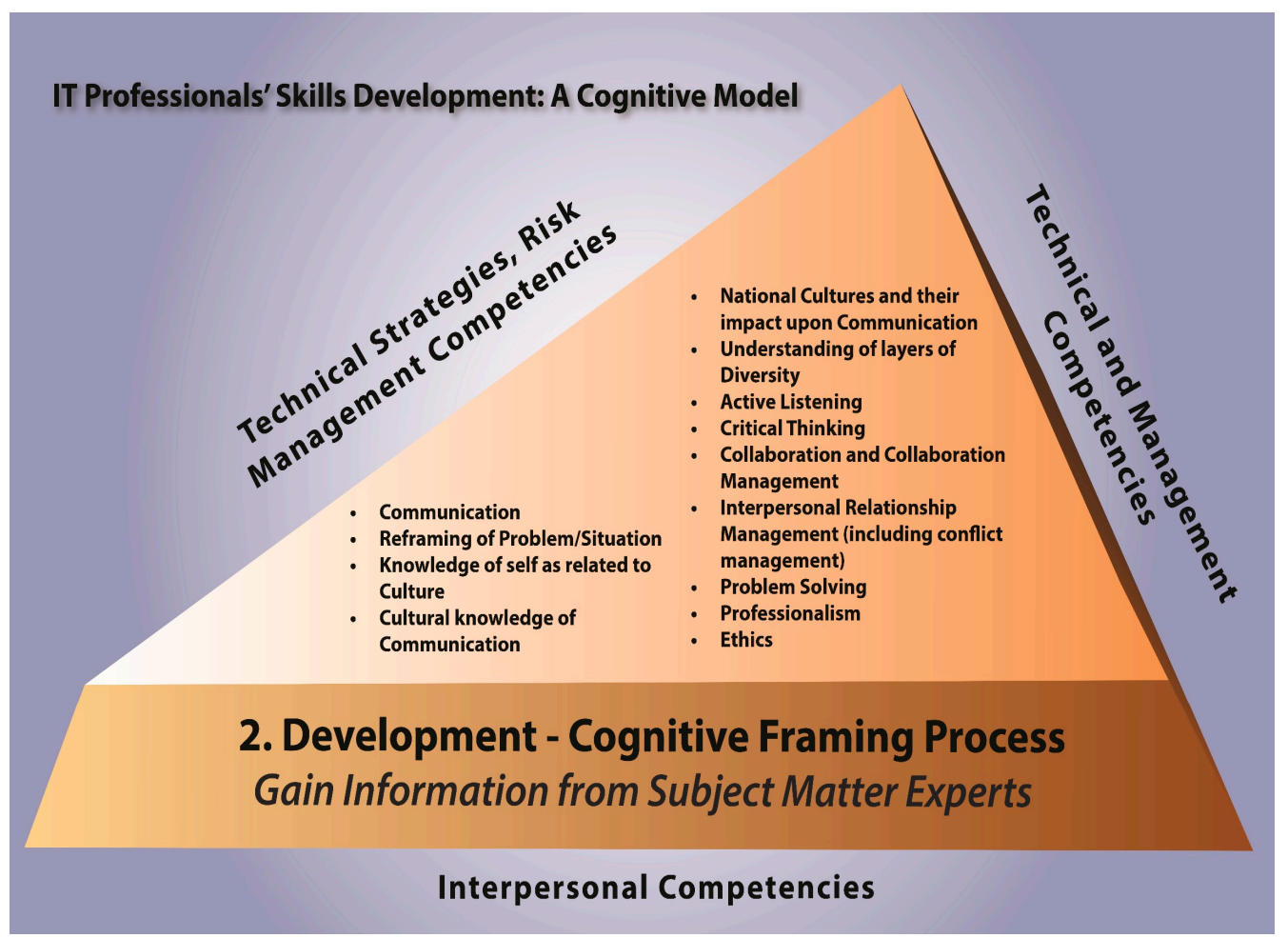

Figure 3. Illustration of the Necessary Non-technical Skills for Step 2: Development-Cognitive Framing Process Social Intuition and Contextual Awareness within a simulated IT Project Systems Development Life Cycle Context.

The process of collaborative problem solving is defined as a learning activity in which interactions between individuals within a group; it is a learning process in which the amount of learning that takes place is related to the level of effort that group members devote to the internal group processes. It results in the development of a shared understanding of the domain of interest [85]. This complex process involves cognitive understanding of multiple social and interpersonal skills; the non-technical knowledge, skills, and practices necessary for successfully engaging in the collaborative problem identification process are identified in Table 3, and further elaborated in Figure 2.

The ability to perceive and identify the cognitive frames of others, especially stakeholders that are essential to the IT success, is essential to the efficacious implementation of any IT work. The understanding of cognitive frameworks is defined as a cognizant and consciousness of stakeholders' frames of reference and perspectives [61]. This knowledge helps individual s to become aware of how others perceive a problem and how they may perceive possible solutions to that problem. Importantly, understanding of perspectives is essential to IT work and processes, which requires IT professionals to collect a great deal of information and collaborate with subject matter experts in multiple organizational functions. The non-technical knowledge, skills, and practices necessary for successfully interpreting cognitive frameworks are identified in Figure 3, and further elaborated in Table 4. 


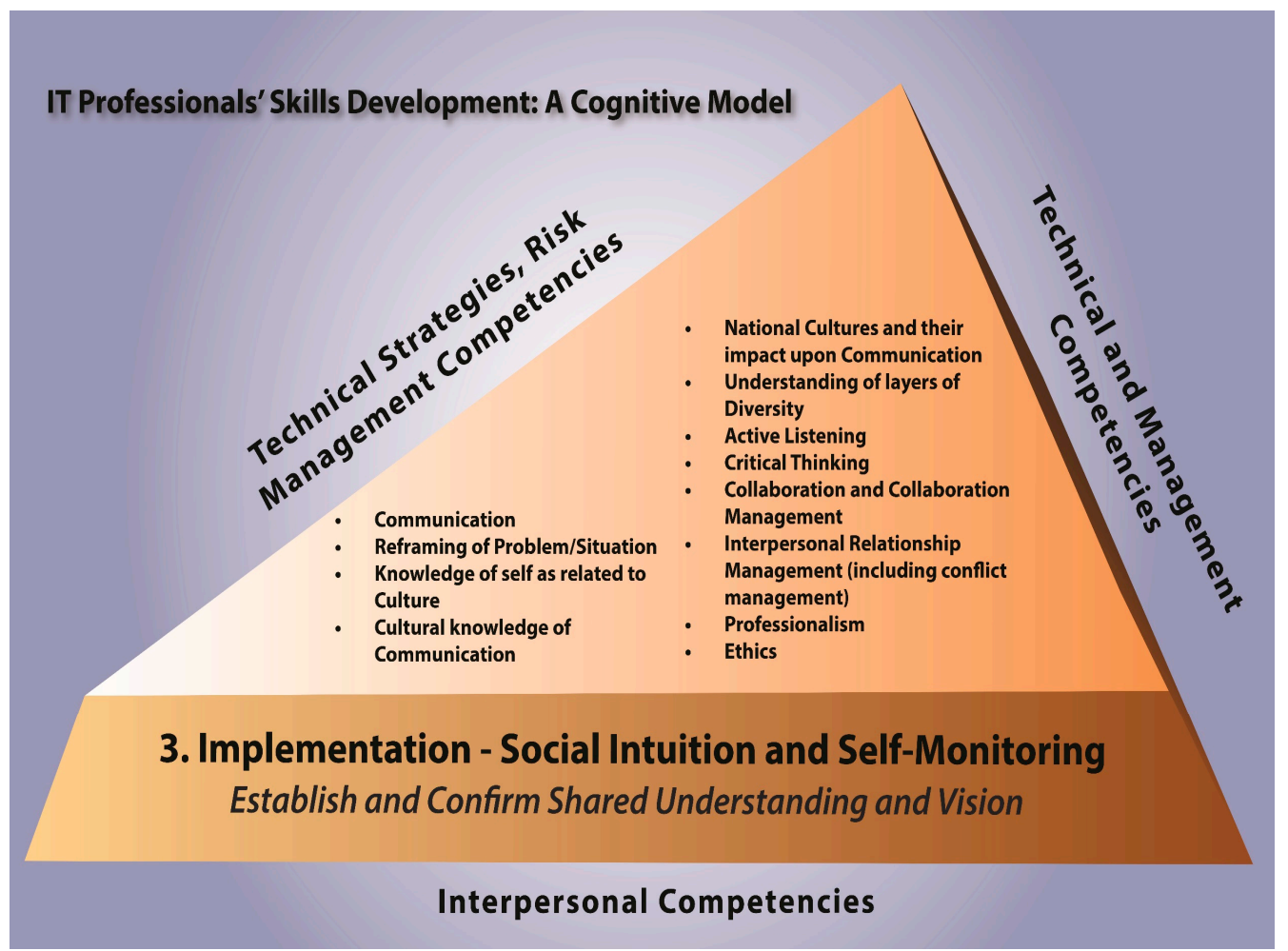

Figure 4. Illustration of the Necessary Non-technical Skills for Step 3: Implementation-Social intuition and self-monitoring Social Intuition and Contextual Awareness within a simulated IT Project Systems Development Life Cycle Context.

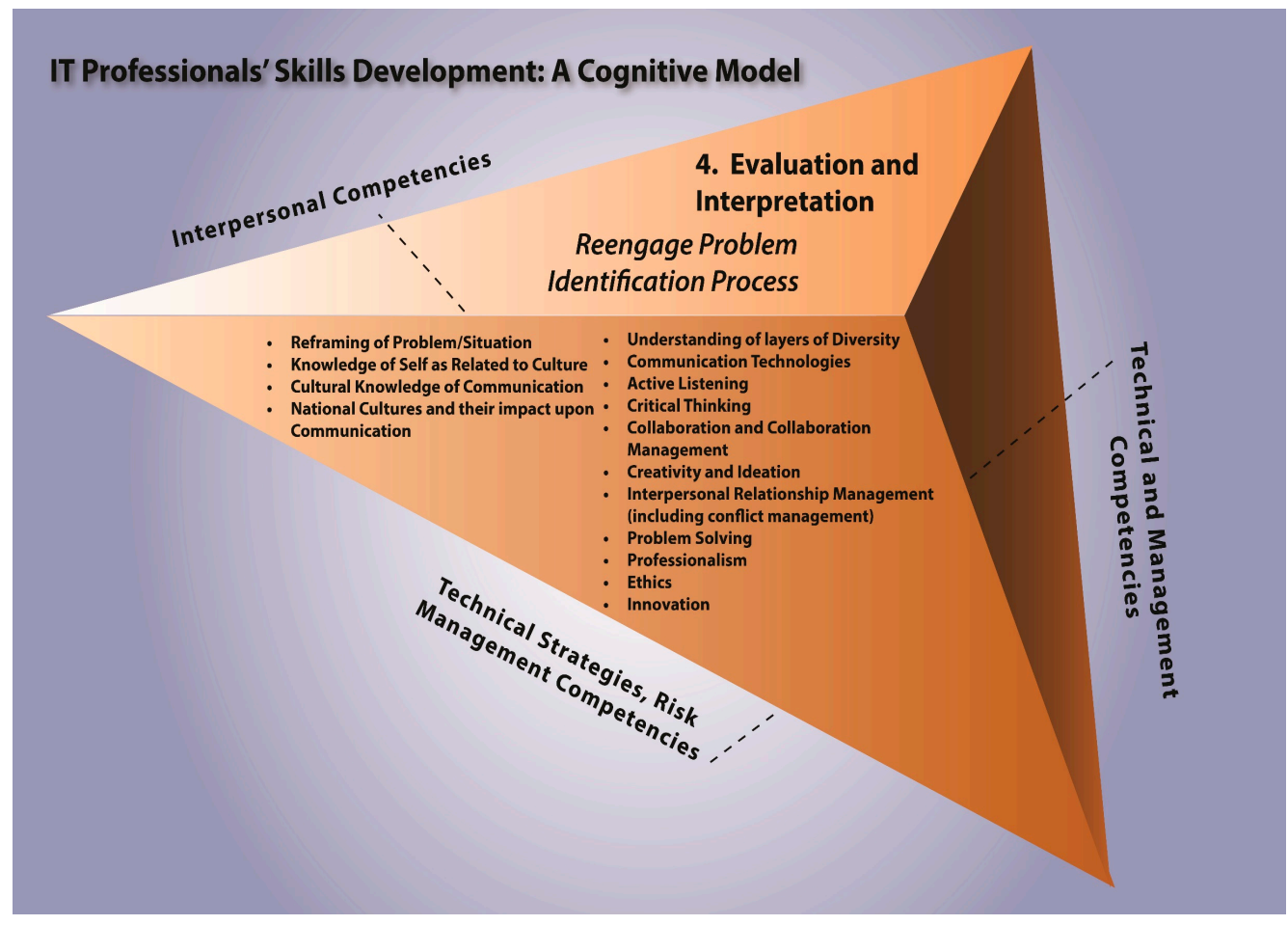

Figure 5. Illustration of the Necessary Non-technical Skills for Step 4: Evaluation and Interpretation: Re-engagement of the Problem Identification Process within the IT Project Systems Development Life Cycle Context. 
Table 3. Typology of non-technical skills for necessary for step 1: concept-problem identification process.

\begin{tabular}{cll}
\hline Area & \multicolumn{1}{c}{ Definition } & \multicolumn{1}{c}{ Non-Technical Knowledge, Skills, and Practices } \\
\hline & & -Communication; \\
& & -Reframing of problem/situation; \\
& A learning activity in which & -Knowledge of self as related to culture; \\
& interactions between individuals & -Cultural knowledge of communication; \\
& within a group aid in learning & -National Cultures and their impact upon communication; \\
& processes. The amount of learning & -Understanding of layers of diversity; \\
Collaborative & -Communication technologies; \\
Problem & that takes place is related to the & -Active listening; \\
Identification & level of effort that group members & -Critical thinking; \\
& devote to the internal group & -Collaboration and collaboration management; \\
& processes; those group processes & -Creativity and ideation; \\
& result in the development of a & -Interpersonal relationship management \\
& shared understanding of the & (including conflict management); \\
& domain of interest [86]. & -Problem-solving; \\
& & -Professionalism; \\
& & -Ethics; \\
& & -Innovation \\
\hline
\end{tabular}

Table 4. Typology of non-technical skills for necessary for step 2: development-cognitive framing process within the IT project context.

\begin{tabular}{cll}
\hline Area & \multicolumn{1}{c}{ Definition } & \multicolumn{1}{c}{ Non-Technical Knowledge, Skills, and Practices } \\
\hline & & -Communication; \\
& & -Reframing of problem/situation; \\
& Cognizance and consciousness of & -Knowledge of self as related to culture; \\
& stakeholders' frames of reference & -Cultural knowledge of communication; \\
& and perspectives help individuals & -National Cultures and their impact upon communication; \\
Cognitive & to become aware of how others & -Understanding of layers of diversity; \\
Frameworks & perceive a problem, and how they & -Active listening; \\
& may perceive possible solutions to & -Critical thinking; \\
& that problem. Adapted from & -Collaboration and collaboration management; \\
& Alexander [41]. & -Interpersonal relationship management \\
& & (including conflict management); \\
& & -Professionalism; \\
& & -Ethics \\
\hline
\end{tabular}

The ability to perceive and identify cues within the context of social interactions, referred to as the Social Intuition and Contextual Awareness, is an essential part of the successful IT implementation. Within the project context, self-monitoring is an individual's ability to pick up social signals, with the help of facial expressions and body language, or the ability to read social cues and develop appropriate responses to those cues based upon very specific contexts. The ability to apply each of these non-technical skills can result in the generation of a better understanding of IT stakeholder needs, a shared understanding of project needs, and creation of a more appropriate visions for an IT project, as identified below in Figure 4 and Table 5.

The process of project evaluation and interpretation involves identifying areas in which an IT project is successful, as well as identifying areas in which further improvements and adjustments are necessary. While we have already identified the necessity to collaborate during early stages of the systems development life cycle, the evaluation process, too, must take place in collaboration with project stakeholders. In this case, collaborative problem solving is defined as a learning and evaluative activity in which interactions between individuals within a group are aimed at evaluating the effectiveness of an IT solution. Again, shared understanding is key [85]. The non-technical knowledge, skills and practices necessary for successfully evaluating the systems development life cycle involved a collaborative problem identification process are identified in Figure 5 and further elaborated in Table 6. 
When engaged in an IT project, students must interpret the need for, and then implement, non-technical skills. Figure 6 integrates all four portions of the simulated IT systems development life cycle.

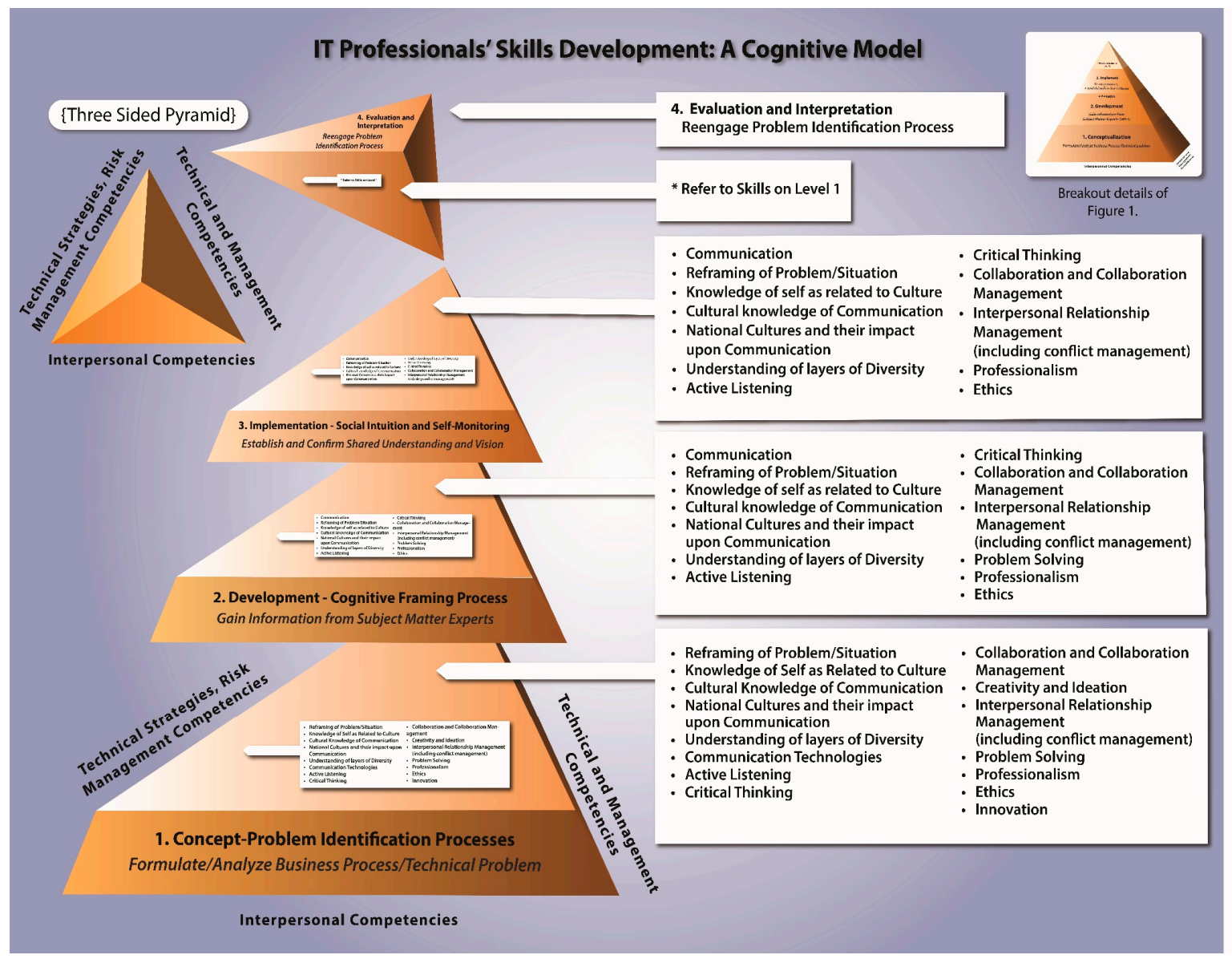

Figure 6. Non-technical Skills Model Integrated into a Simulated IT Project through the entire Systems Development Life Cycle.

Table 5. Typology of non-technical skills for necessary for step 3 implementation-social intuition and self-monitoring.

\begin{tabular}{cll}
\hline Area & \multicolumn{1}{c}{ Definition } & \multicolumn{1}{c}{ Non-technical Knowledge, Skills, and Practices } \\
\hline & & -Communication; \\
& & -Reframing of problem/situation; \\
& An individual's ability to pick up & -Knowledge of self as related to culture; \\
social signals with the help of & -Cultural knowledge of communication; & -National Cultures and their impact upon communication; \\
Social Intuition and & facial expressions and body & -Understanding of layers of diversity; \\
Self-Monitoring/ & language; our ability read social & -Active listening; \\
Contextual & cues, and then develop & -Critical thinking; \\
Awareness & appropriate responses to those & -Collaboration and collaboration management; \\
& cues based upon very specific & -Interpersonal relationship management \\
& contexts. Adapted from Davidson & (including conflict management); \\
& and Begley [93]. & -Problem-solving; \\
& & -Professionalism; \\
& & -Ethics \\
\hline
\end{tabular}


Table 6. Typology of non-technical skills necessary for step 4: evaluation and interpretation: re-engagement of problem identification process.

\begin{tabular}{|c|c|c|}
\hline Area & Definition & Non-technical Knowledge, Skills, and Practices \\
\hline $\begin{array}{l}\text { Re-engage } \\
\text { Problem } \\
\text { Identification }\end{array}$ & $\begin{array}{l}\text { A learning and evaluative activity } \\
\text { in which interactions between } \\
\text { individuals within a group; it is a } \\
\text { learning process in which the } \\
\text { amount of learning that takes } \\
\text { place is related to the level of effort } \\
\text { that group members devote to the } \\
\text { internal group processes. These } \\
\text { result in the development of a } \\
\text { shared understanding of the } \\
\text { domain of interest [92]. }\end{array}$ & $\begin{array}{l}\text {-Communication; } \\
\text {-Reframing of problem/situation; } \\
\text {-Knowledge of self as related to culture; } \\
\text {-Cultural knowledge of communication; } \\
\text {-National Cultures and their impact upon communication; } \\
\text {-Understanding of layers of diversity; } \\
\text {-Communication technologies; } \\
\text {-Active listening; } \\
\text {-Critical thinking; } \\
\text {-Collaboration and collaboration management; } \\
\text {-Creativity and ideation; } \\
\text {-Interpersonal relationship management } \\
\text { (including conflict management); } \\
\text {-Problem-solving; } \\
\text {-Professionalism; } \\
\text {-Ethics; } \\
\text {-Innovation }\end{array}$ \\
\hline
\end{tabular}

\section{Implications and Conclusions}

The development of curriculum that includes a holistic and thorough approach to teaching non-technical skills within higher education IT curricula is important in several ways. First, it has implications for organizations who hire recent graduates; their expectations for incoming employees that have the requisite non-technical skills is critical for successful organizational processes and products. The improvement of non-technical skills in the IT workforce will help ensure the successful formulation, execution, and completion of IT projects that are both technically sound, and provide a basis for developing competitive advantage.

Second, the development of non-technical skills has implications for IT product end-users. Improvement of non-technical skills within the IT workforce would be meaningful to the end-user experience inasmuch as a more collaborative, consultative process results in more useful end products. IT practitioners have the non-technical knowhow to provide end users with more collaborative involvement in the early stages of IT projects improve the likelihood of a successful project outcome from a customer perspective, as suggested by Lieberman [97].

Finally, the development of non-technical skills has implications for IT professionals, themselves. The improvement of these skills may have impacts both personally and professionally, as the ability of IT workers becomes increasingly more adept at understanding the social, psychological, and political factors that provide the contextual background in which IT projects are developed and completed. Improvements in interpersonal relationships, communications skills, relationship management, and understanding of diversity and diverse perspectives will culminate in insights and intuition into how they might better interact within complex IT contexts, thus creating a more positive experience for both the individual, and those $\mathrm{s} / \mathrm{he}$ is working with.

This research also has some theoretical implications. Few published, scholarly articles have attempted to coalesce a holistic set of non-technical skills from the literature. The development of a typology such as this provides scholars and practitioners a guidepost from which new curricular models can be developed. With calls for improved non-technical skills within the IT workforce, this review, and the resulting model, helps to demonstrate how, and in what areas, improvements in non-technical skills will impact the IT project systems development life cycle.

The purpose of this paper was three-fold. First, its purpose was to identify areas of IT that were considered essential for IT success. Second, it aimed to identify those portions of the literature that are considered important to the non-technical skills. Finally, it intended to design a holistic conceptual framework for integrating instruction of non-technical skills into the IT curriculum. We set out to 
accomplish this by reviewing the literature and developing a specific list of required non-technical skills using a cross-disciplinary, practice-oriented framework that was based upon success factors known to be critical to IT success. Based on the work of several authors [21,25,37-47,49-61], the list is both exhaustive and encompassing, and identifies areas essential for the development of appropriate IT curricula.

In taking the success factors noted above and applying those to curricular changes via an algorithmic method for instruction, we argue that the intuitive nature of algorithmic instruction for non-technical skills promotes IT students' understanding by using a method that is already widely applied within IT education [79-81] and, therefore, may be more relevant for IT students. We are not alone in our enthusiasm for using algorithms to aid in student learning and development $[79,80]$ - the use of an algorithmic approach may help to disseminate these skills in a way that is both accessible and comprehensible to IT and IS students, as suggested by others [81,96]. The use of algorithms as a pedagogical strategy for developing the skill of "working with others" may help to reduce the complexity of the social-cognitive processes necessary to make effective non-technical skills-type decisions, thus improving professionals' ability to quickly make appropriate decisions that can ultimately improve cooperative processes and ultimately influence within organizations, all of which are essential to the overall success of IT professionals.

By applying what is already known about (a) the non-technical skills needed for IT success; (b) IT pedagogy; (c) the current use of algorithmic thinking across several disciplines; and (d) the inclusion of a simulated project across the systems development life cycle, we have made the case for a new pedagogical framework that addresses the needs expressed by the business community for improved instruction in non-technical skills. Importantly, our attempt to address non-technical skills is in response to the educational needs expressed by the business community, as noted above $[1,2,6]$ helps to establish higher education within the public domain as the most viable source of training and development for its workforce. This is important as IT education must work to remain relevant in a quickly maturing and dynamic area-higher education programs that respond to workforce needs and can provide an appropriate set of non-technical skills training, while retaining excellent training and development of technical competencies, are the ones that do not lag behind industry [73]. Further, the development of a taxonomy help to define an inclusive model for describing, classifying, and ultimately teaching non-technical skills for these audiences. This, in turn is based upon prior research, which helps to build a bridge between current literature and practice.

The research cited above calls for IT professions, both managers and employees, who are (a) adept at creating and maintaining strong interpersonal relationships [34,37,83]; (b) excellent communicators with the ability to communicate expectations, provide guidance and championship, and work with and develop strength from diversity [20,27-31,46,50,58]; (c) able to listen actively and carefully to customer expectations and requirements, and reframe thinking based upon information available [19,37]; and (d) able to think critically, creatively, and innovatively both in regular domains and within new domains, such as social media and other outlets with professionalism and ethics $[24,26,32,34,36]$. The application of critical success factors and thorough literature review are important steps in identifying those non-technical skills that are crucial for success.

With increased complexity in organizations, an ever-growing body of technology, and an ever-shrinking time available to address important organizational issues, it is essential that IT and IS professionals are able to identify problems and create solutions that help their organizations-the necessary solutions can only come from successful collaborative efforts [21-23,44]. In addition to traditional challenges faced by IT professionals, new technologies that reside outside of our current domain and paradigm call for innovative thinking and strong critical analysis skills and, therefore, strong collaborative and convergence skills [69], each of which require the ability to work with others.

Thus, the taxonomy and resulting model provide the structure for pedagogical learning components that can guide the development of instruction on non-technical skills within the project context within IT higher education. All of this will help to answer the call from business leaders 
to provide "well-rounded" IT professionals [4], a professional call that can be answered through improvements to IT curriculum that includes strong non-technical skills instituted into the more technically-related coursework of traditional IT university programs.

Acknowledgments: Initial research supporting this paper was conducted with the support of AdvanceIT, the Center of Excellence for IT in Minnesota State Universities (formerly MnSCU).

Author Contributions: David Bouchard conceptualized the topic; Marcia Hagen and David Bouchard conceived and designed the pedagogical model; Marcia Hagen performed the literature review; David Bouchard conceptualized and designed visualizations and figures; Marcia Hagen wrote the paper in consultation with David Bouchard.

Conflicts of Interest: The authors declare no conflict of interest. The founding sponsors had no role in the design of the study; in the collection, analyses, or interpretation of data; in the writing of the manuscript, and in the decision to publish the results.

\section{References}

1. Wilder Foundation. Information Technology Industry Sector Preliminary Themes; Unpublished typescript; Wilder Foundation: St. Paul, MN, USA, 2012.

2. Meeting Minnesota's Workforce Needs; Minnesota State Colleges and Universities: St Paul, MN, USA, 2012; Available online: http:/ / www.mnscu.edu/business/workforceassessment/doc/IT\%20Workforce\% 20Summary-09\%202012.pdf (accessed on 15 June 2016).

3. Andrews, J.; Higson, H. Graduate employability, 'soft skills' versus 'hard' business knowledge: A European study. High. Educ. Eur. 2008, 33, 411-422. [CrossRef]

4. Bassellier, G.; Benbasat, I. Business competence of information technology professionals: Conceptual development and influence on IT-business partnerships. MIS Q. 2004, 28, 673-694.

5. Zhang, L.; Jones, M. Can social capital enhance the careers of IT professionals? Inf. Resour. Manag. J. 2009, 22, 69-82. [CrossRef]

6. Shields, K.; Johnson, J.A. Report of the Rhode Island Information Technology Skills Gap Task Force; Rhode Island Governors' Workforce Board: Cranston, RI, USA, 2008.

7. Kasper, G. Information technology and individualized mass higher education. Inf. Resour. Manag. J. 1996, 9, 3-4.

8. Aasheim, C.L.; Li, L.; Williams, S. Knowledge and skill requirements for entry-level information technology workers: A comparison of industry and academia. J. Inf. Syst. Educ. 2009, 20, 349.

9. Beard, D.; Schwieger, D.; Surendran, K. Integrating soft skills assessment through university, college, and programmatic efforts at an AACSB accredited institution. J. Inf. Syst. Educ. 2008, 19, 229-240.

10. Cox, S.; King, D. Skill sets: An approach to embed employability in course design. Educ. Train. 2006, 48, 262-274. [CrossRef]

11. Blumenberg, S.; Beimborn, D.; Koenig, W. Determinants of IT outsourcing relationships: A conceptual model. In Proceedings of the 41st Annual Hawaii International Conference on System Sciences, Waikoloa, HI, USA, 7-10 January 2008.

12. Brody, R.; Bird, S.; Xin, R.L.; Seazzu, A. Social engineering: The neglected human factor for information security management. Inf. Resour. Manag. J. 2011, 24, 1-8.

13. Marcello, C.V. A Correlational Analysis: Perceptions of Workplace Bullying and Psychological Empowerment among IT Professionals. Ph.D. Thesis, University of Phoenix, Tempe, AZ, USA, 2010.

14. Bloomfield, B.P.; Danieli, A. The role of management consultants in the development of information technology: The indissoluble nature of socio-political and technical skills. J. Manag. Stud. 1995, 32, 23-46. [CrossRef]

15. Torraco, R.J. Writing integrative literature reviews: Guidelines and examples. Hum. Resour. Dev. Rev. 2005, 4, 356-367. [CrossRef]

16. Richards, L. Handling Qualitative Data: A Practical Guide; Sage: Thousand Oaks, CA, USA, 2014.

17. Robles, M. Executive perceptions of the top 10 soft skills needed in today's workplace. Bus. Commun. Q. 2012, 4, 453-465. [CrossRef]

18. Nealy, C. Integrating soft skills through active learning in the management classroom. J. Coll. Teach. Learn. 2005, 2. [CrossRef] 
19. $\mathrm{Xu}, \mathrm{F}$. The Priority of Listening Comprehension over Speaking in the Language Acquisition Process. Int. Educ. Stud. 2011, 4, 161-165. [CrossRef]

20. Kreps, G.L. Relational communication in health care. South. Speech Commun. J. 1988, 53, 344-359. [CrossRef]

21. Barratt, M. Understanding the meaning of collaboration in the supply chain. Supply Chain Manag. 2004, 9, 30-42. [CrossRef]

22. Stank, T.; Crum, M.; Arango, M. Benefits of interfirm coordination in food industry supply chains. J. Bus. Logist. 1999, 20, 21-41.

23. Baker, D.; Georgakopoulos, D.; Schuster, H.; Cassandra, A.; Cichocki, A. Providing customized process and situation awareness in the collaboration management infrastructure. In Proceedings of the 1999 IFCIS International Conference on Cooperative Information Systems, Edinburgh, Scotland, 2-4 September 1999; pp. 79-91.

24. Fulk, J. Social construction of communication technology. Acad. Manag. J. 1993, 36, 921-950. [CrossRef]

25. Ryhammar, L.; Brolin, C. Creativity research: Historical considerations and main lines of development. Scand. J. Educ. Res. 1999, 43, 259-273. [CrossRef]

26. Norris, S.P. Synthesis of research on critical thinking. Educ. Leadersh. 1985, 42, 40-45.

27. Hall, E.T. Beyond Culture; Anchor Books: New York, NY, USA, 1976.

28. Hofstede, G. National cultures in four dimensions: A research-based theory of cultural differences among nations. Int. Stud. Manag. Organ. 1983, 13, 46-74. [CrossRef]

29. Victor, D.A. International Business Communication; Harper-Collins: New York, NY, USA, 1994.

30. Kinicki, A.; Kreitner, R. Organizational Behavior: Key Concepts, Skills \& Best Practices; McGraw-Hill/Irwin: Tallahases, FL, USA, 2003.

31. Gardenswartz, L.; Rowe, A. The Managing Diversity Survival Guide: A Complete Collection of Checklists, Activities, and Tips; McGraw-Hill: Tallahases, FL, USA, 1994.

32. Lewis, P.V. Defining 'business ethics': Like nailing jello to a wall. J. Bus. Ethics 1985, 4, 377-383. [CrossRef]

33. Rockart, J.F. The changing role of the information systems executive: A critical success factor perspective. Sloan Manag. Rev. 1982, 24, 3-13.

34. Cropanzano, R.; Mitchell, M.S. Social Exchange Theory: An Interdisciplinary Review. J. Manag. 2005, 31, 874-900. [CrossRef]

35. D'Zurilla, T.J.; Nezu, A.M. Problem-Solving Therapy. Handbook of Cognitive-Behavioral Therapies; The Guilford Press: New York, NY, USA, 2010; pp. 197-225.

36. VanZandt, C.E. Professionalism: A matter of personal initiative. J. Couns. Dev. 1990, 68, 243-245. [CrossRef]

37. Bolman, L.G.; Deal, T.E. Reframing Organizations: Artistry, Choice, and Leadership; Jossey-Bass: San Francisco, CA, USA, 2007.

38. Russo, J.E.; Schoemaker, P.J.H. Winning Decisions; Random House: New York, NY, USA, 2002.

39. Brent, R.; Anderson, P. Developing children's classroom listening strategies. Read. Teach. 1993, 47, $122-126$.

40. Jalongo, M.R. Promoting active listening in the classroom. Child. Educ. 1995, 72, 13-18. [CrossRef]

41. Cavalier, J.C.; Klein, J.D.; Cavalier, F.J. Effects of cooperative learning on performance, attitude, and group behaviors in a technical team environment. Educ. Technol. Res. Dev. 1995, 43, 61-72. [CrossRef]

42. Kim, Y.; Addom, B.K.; Stanton, J.M. Education for eScience professionals: Integrating data curation and cyberinfrastructure. Int. J. Digit. Curation 2011, 6, 125-138. [CrossRef]

43. Archibugi, D.; Iammarino, S. The globalization of technological innovation: Definition and evidence. Rev. Int. Polit. Econ. 2002, 9, 98-122. [CrossRef]

44. Malhotra, A.; Majchrzak, A.; Carman, R.; Lott, V. Radical innovation without collaboration: A case study at Boeing-Rocketdyne. MIS Q. 2001, 25, 229-249. [CrossRef]

45. Cooper, R.B. Information technology development creativity: A case study of attempted radical change. MIS Q. 2000, 24, 245-276. [CrossRef]

46. Michalko, M. Thinkertoys: A Handbook of Creative-Thinking Techniques; Ten Speed Press: Berkeley, CA, USA, 2010.

47. Du Plessis, M. The role of knowledge management in innovation. J. Knowl. Manag. 2007, 11, 20-29. [CrossRef]

48. Dahl, D.W.; Moreau, P. The influence and value of analogical thinking during new product ideation. J. Mark. Res. 2002, 39, 47-60. [CrossRef]

49. Ames, M.; Runco, M.A. Predicting entrepreneurship from ideation and divergent thinking. Creativity Innov. Manag. 2005, 14, 311-315. [CrossRef] 
50. Ennis, R.H. A logical basis for measuring critical thinking skills. Educ. Leadersh. 1985, 43, 44-48.

51. Ivanov, K. Critical systems thinking and information technology: Some summary reflections, doubts, and hopes through critical thinking critically considered, and through hypersystems. J. Appl. Syst. Anal. 1991, 18, 39-55.

52. Bruce, C.S. Workplace experiences of information literacy. Int. J. Inf. Manag. 1999, 19, 33-48. [CrossRef]

53. Shachaf, P. Cultural diversity and information and communication technology impacts on global virtual teams: An exploratory study. Inf. Manag. 2008, 45, 131-142. [CrossRef]

54. Gaul, S.; Wilkowska, W.; Ziefle, M. Accounting for user diversity in the acceptance of medical assistive technologies. In Proceedings of the 3rd International ICST Conference on Electronic Healthcare for the 21st Century, Casablanca, Morocco, 13-15 December 2010.

55. Dunaway, M.M. IS Learning: The Impact of Gender and Team Emotional Intelligence. J. Inf. Syst. Educ. 2013, 24, 189-202.

56. Weigelt, C.; Sarkar, M. Learning from supply-side agents: The impact of technology solution providers' experiential diversity on clients' innovation adoption. Acad. Manag. J. 2009, 52, 37-60. [CrossRef]

57. Longstaff, T.A.; Chittister, C.; Pethia, R.; Haimes, Y. Are we forgetting the risks of information technology? Computer 2000, 33, 43-51. [CrossRef]

58. Collins, N.L.; Read, S. Adult attachment, working models, and relationship quality in dating couples. J. Personal. Soc. Psychol. 1990, 58, 644-663. [CrossRef]

59. Junnarkar, B.; Brown, C.V. Re-assessing the enabling role of information technology in KM. J. Knowl. Manag. 1997, 1, 142-148. [CrossRef]

60. Ley, T.; Seelmeyer, U. Profesionalism and Information Technolgy: Positining and mediation. Soc. Work Soci. Int. Online J. 2008, 6, 338-351.

61. Ariyachandra, T.R.; Frolick, M.N. Critical success factors in business performance management-Striving for success. Inf. Syst. Manag. 2008, 25, 113-120. [CrossRef]

62. Lawson-Body, A.; Willoughby, L.; Mukankusi, L.; Logossah, K. The critical success factors for public sector CRM implementation. J. Comput. Inf. Syst. 2011, 52, $42-54$.

63. Biehl, M. Success factors for implementing global information systems. Commun. ACM 2007, 50, 52-58. [CrossRef]

64. Wong, K.Y. Critical success factors for implementing knowledge management in small and medium enterprises. Ind. Manag. Data Syst. 2005, 105, 261-279. [CrossRef]

65. Poon, P.P.; Wagner, C. Critical success factors revisited: Success and failure cases of information systems for senior executives. Decis. Support Syst. 2001, 30, 393-418. [CrossRef]

66. Sommers, T.M.; Nelson, K. The impact of critical success fators acorss stages of enterprise resource planning systems. In Proceedings of the 34th Annual Hawaii International Conference on Systems Sciences, Maui, HI, USA, 6 January 2001.

67. Nah, F.F.H.; Lau, J.L.S.; Kuang, J. Critical factors for successful implementation of enterprise systems. Bus. Process Manag. J. 2001, 7, 285-296.

68. Frolick, M.N.; Ariyachandra, T.R. Business performance management: One truth. Inf. Syst. Manag. $2006,23$. [CrossRef]

69. Lee, J.H.; Shim, H.J.; Kim, K.K. Critical success factors in SOA implementation: An exploratory study. Inf. Syst. Manag. 2010, 27, 123-145. [CrossRef]

70. Chow, T.; Cao, D.B. A survey study of critical success factors in agile software projects. J. Syst. Softw. 2008, 81, 961-971. [CrossRef]

71. Taylor, H.; Woelfer, J.P. Behavioral Competencies and Learning Methods for Information Technology Project Management: An Exploratory Study. In Proceedings of the 4th International Research Workshop on Information Technology Project Management, Phoenix, AZ, USA, 14 December 2009.

72. Woodward, B.; Sendall, P.; Ceccucci, W. Integrating soft skill competencies through project-based learning across the information systems curriculum. Inf. Syst. Educ. J. 2010, 8, 1-15.

73. Olson, J.R. The sky's the limit: An activity for teaching project management. J. Manag. Educ. 2006, 30, 404-20.

74. Loch, C.H.; De Meyer, A.; Pich, M.T. A Broader Look at Project Risk Management. In Managing the Unknown: A New Approach to Managing High Uncertainty and Risk in Projects; John Wiley \& Sons, Inc.: Hoboken, NJ, USA, 2006. 
75. Deininger, M.; Schneider, K. Teaching software project management by simulation—Experiences with a comprehensive model. In Software Engineering Education; Springer Berlin: Heidelberg, Germany, 1994; pp. 227-242.

76. Helle, L.; Tynjälä, P.; Olkinuora, E. Project-based learning in post-secondary education-theory, practice and rubber sling shots. High. Educ. 2006, 51, 287-314. [CrossRef]

77. Eteläpelto, A. The Development of Expertise in Information Systems Design; University of Jyväskylä: Jyväskylä, Finland, 1998.

78. Morgan, A. Theoretical Aspects of Project-Based Learning in Higher Education. Br. J. Educ. Technol. 1983, 14, 66-78. [CrossRef]

79. Nunamaker, J.; Chen, M.; Purdin, T. Systems development in information systems research. J. Manag. Inf. Syst. 1990, 7, 89-106. [CrossRef]

80. Dagdilelis, V.; Satratzemi, M.; Evangelidis, G. Introducing secondary education students to algorithms and programming. Educ. Inf. Technol. 2004, 9, 159-173. [CrossRef]

81. Chaitin, G.J. Thoughts on the Riemann hypothesis. Math. Intell. 2004, 26, 4-7. [CrossRef]

82. Ormrod, J. Human Learning; Pearson Prentice Hall: Upper Saddle River, NJ, USA, 2008.

83. Frank, D.V.; Baker, C.A.; Heron, J.D. Should students always use algorithms to solve problems? In Proceedings of the 190th National Meeting of the American Chemical Society, Chicago, IL, USA, 8-13 September 1985.

84. Lau, R.R.; Redlawsk, D. Advantages and disadvantages of cognitive heuristics in political decision making. Am. J. Polit. Sci. 2001, 45, 951-971. [CrossRef]

85. Dillenbourg, P.; Traum, D. Sharing solutions: Persistence and grounding in multimodal collaborative problem solving. J. Learn. Sci. 2006, 15, 121-151. [CrossRef]

86. Antunes, P.; Santos, R.; Videira, N. Participatory decision making for sustainable development-The use of mediated modelling techniques. Land Use Policy 2006, 23, 44-52. [CrossRef]

87. Ribbers, P.M.A.; Peterson, R.R.; Parker, M.M. Designing information technology governance processes: Diagnosing contemporary practices and competing theories. In Proceedings of the 35th Annual Hawaii International Conference on System Sciences, Big Island, HI, USA, 7-10 January 2002; pp. 3143-3154.

88. Anderson, C.R.; Paine, F.T. Managerial perceptions of strategic behavior. Acad. Manag. J. 1975, 18, $811-823$. [CrossRef]

89. Nonacs, P. Is satisficing an alternative to foraging theory? Oiko 1993, 67, 371-384. [CrossRef]

90. Dutton, J.; Fahey, L.; Narayanan, V. Toward understanding strategic issue diagnosis. Strateg. Manag. J. 1983, 4, 307-323. [CrossRef]

91. Davidson, R.J.; Begley, S. The Emotional Life of Your Brain; Hudson Street Press: New York, NY, USA, 2012.

92. Lennox, R.D.; Wolfe, R.N. Revision of the self-monitoring scale. J. Personal. Soc. Psychol. 1984, 46, 1349-1364. [CrossRef]

93. Leary, M.R.; Kowalski, R.M. Impression management: A literature review and two-component model. Psychol. Bull. 1990, 107, 34-47. [CrossRef]

94. Day, D.V.; Schleicher, D.J.; Unckless, A.L.; Hiller, N.J. Self-monitoring personality at work: A meta-analytic investigation of construct validity. J. Appl. Psychol. 2002, 87, 390-401. [CrossRef] [PubMed]

95. Dennett, D.C. The evolution of reasons. In Contemporary Philosophical Naturalism and Its Implications; Routledge: London, UK, 2013.

96. Schwalbe, K. Information Technology Project Management; Cengage Learning: Hampshire, UK, 2015.

97. Lieberman, H.; Paternò, F.; Wulf, V. End User Development; Springer: Doerdract, The Netherlands, 2006.

(c) 2016 by the authors; licensee MDPI, Basel, Switzerland. This article is an open access article distributed under the terms and conditions of the Creative Commons Attribution (CC-BY) license (http://creativecommons.org/licenses/by/4.0/). 